\title{
The pattern of gene expression and possible relation of steroidogenic genes in oligodendroglial tumors
}

\author{
HO JUN SEOL ${ }^{1}$, JEONG EUN KIM ${ }^{2}$, KYU-CHANG WANG ${ }^{2}$, SEUNG-KI KIM ${ }^{2}$, \\ JEONG-SUN SEO ${ }^{3}$, SUNG-HYE PARK ${ }^{4}$ and HEE-WON JUNG ${ }^{2}$ \\ ${ }^{1}$ Department of Neurosurgery, Kangwon National University College of Medicine, 26 Kangwon-daehangno, \\ Chuncheon 200-947; Departments of ${ }^{2}$ Neurosurgery, ${ }^{3}$ Biochemistry and Molecular Biology, \\ ILCHUN Molecular Medicine Institute MRC and ${ }^{4}$ Pathology, Seoul National University \\ College of Medicine, 28 Yeongeon-dong Jongno-gu, Seoul 110-744, Korea
}

Received August 18, 2008; Accepted October 20, 2008

DOI: 10.3892/ijo_00000140

\begin{abstract}
Steroidogenic acute regulatory protein (StAR) regulates the rate-determining step of steroidogenesis. StAR is expressed at a very low level in the white matter of the normal human brain, but is highly expressed in several brain neoplasms including oligodendroglioma (OD). The aim of this study was to identify the different patterns of gene expression low-grade OD and high-grade OD. We carried out gene expression profiling and analyzed the data. In addition, real-time PCR using StAR primer and immunofluorescent study for StAR were performed. There was a difference in genetic expression between low- and high-grade ODs. An elevated expression of several genes involved in lipid and steroid synthesis, compared with normal white matter, was observed. The expression of such genes showed a tendency either of decreasing or mildly increasing, in high-grade ODs, compared with low-grade ODs. Real-time PCR showed that expression of StAR was relatively low in high-grade ODs, in comparison with low-grade ODs. The pattern of expression between low- and high-grade ODs can differ. This study suggests that the mechanism of neurosteroids synthesis through StAR can be related to the growth of ODs.
\end{abstract}

\section{Introduction}

Oligodendroglial tumor (OD) is an uncommon neoplasm that constitutes $2-7 \%$ of primary brain tumors. In general, the treatment of OD consists of maximum feasible surgery, followed by radiotherapy. However, recurrence and prog-

Correspondence to: Dr Jeong Eun Kim, Department of Neurosurgery, Seoul National University College of Medicine, 28 Yeongeon-dong Jongno-gu, Seoul 110-744, Korea

E-mail: eunkim@snu.ac.kr or eunkimns@paran.com

Key words: gene expression profiling, neurosteroid, steroidogenic acute regulatory protein, oligodendroglial tumor ression to malignancy are major problems in the treatment of this tumor (1).

The cytogenesis of OD remains a debatable issue, because evidence supporting the oligodendrocyte as the 'cell of origin' of OD is inconsistent. Nonetheless, many researchers agree that investigation of oligodendrocytes is indispensable to understanding OD cells, because the latter are believed to have strong histochemical connection to the former. Oligodendrocytes are the myelinating cells of the central nervous system, ensheathing axons with a specialized, multilayered, membranous wrapping that facilitates saltatory neuronal conduction (2). Previously, it was proven that oligodendrocytes derived from human brain have peripheral-type benzodiazepine receptor and can produce neurosteroids such as pregnenolone (3). Many steroidogenic enzymes, which are identical to those in the adrenal glands, have been found in the human brain (4). The human brain is just as much a steroidogenic organ as are the endocrine glands. Therefore, it is suggested that oligodendrocytes play an important role in neurosteroidogenesis in the human brain.

Steroidogenic acute regulatory protein (StAR), P450 sidechain cleavage enzyme (P450scc) and 3 ß-hydroxysteroid dehydrogenase enzyme (3ß-HSD) enzymes are involved in the transport of cholesterol and the production of progesterone, where P450scc converts cholesterol into pregnenolone, which is further transformed into progesterone by 3ß-HSD (5). $\mathrm{P} 450 \mathrm{scc}$ has been detected in the white matter throughout the brain of rats and humans $(6,7)$.

Meanwhile, to investigate the molecular characteristics of the tumors, several researchers have suggested the efficacy of gene expression array in ODs (8-11). They revealed that several genes related to nucleic acid metabolism, cell proliferation, transcription and translation, migration, and signal transduction, etcetera, were more up-regulated as the OD grade increased. Decreased expression in the immunological response of the host, normal development, neurotransmission and in other measures was observed in the genes. In addition, hierarchical clustering and gene profiling were well correlated with the tumor grade and prognosis. However, there have been no studies revealing the relation of neurosteroidogenesis and ODs. Therefore, we performed this 
study focusing on neurosteroid-related genes to identify the global pattern of gene expression and to determine whether expression of the genes related to steroidogenesis could make a difference between ODs and the normal brain.

\section{Materials and methods}

Patients and tissue specimens. We evaluated specimens from 10 cases each of low-grade OD and high-grade OD (Table I). All of these archival specimens were retrieved from the tumor database at the Department of Neurosurgery, Seoul National University Hospital. The patient's ages ranged from 26 months to 68 years (median 37 years). Ethical approval was obtained in accordance with the Institutional Review Board of Seoul National University College of Medicine and Seoul National University Hospital (SNUMC/SNUH IRB: R-0603-256-172). Two pathologists performed careful review of the pathological slides and mixed glial tumors such as oligoastrocytomas could be ruled out.

Pathological grades were determined and reviewed according to the criteria of the World Health Organization. Freshly frozen specimens were available for real-time PCR analysis in 20 cases. Specimens for RNA isolation were immediately frozen in liquid nitrogen and stored at $-70^{\circ} \mathrm{C}$. We obtained human brain tissue from a patient with medial temporal lobe epilepsy after informed consent had been received. Gray matter and white matter were divided after anterior temporal lobectomy in the operative room.

Gene expression microarray in ODs and normal white matter. Three tumor samples each of low-grade and high-grade ODs were investigated (LOD-3, $-6,-10$ and HOD-5, -9, -10). One sample of normal white matter was used as a control. For experimental validity, technical replication of the normal control (Nl-1 and Nl-2) was performed. A commercial kit of Applied Biosystem genome chip (Macrogen, Seoul, Korea) containing 31,700 targets including 27,868 genes was used. Total RNA was prepared from tissues using Invitrogen Life Technologies' TRIzol reagent (Life Technologies, Gaithersburg, MD). Thereafter, samples of sufficient quality and quantity of RNA were further analyzed. Two $\mu \mathrm{g}$ of total RNA was used to generate double-strand cDNA according to the manufacturer's protocol. Digoxigenin-labeled antisense cRNA was synthesized by in vitro transcription using Applied Biosystems Chemiluminescent RT-IVT Labeling kit (Macrogen). Ten $\mu \mathrm{g}$ of cRNA was chemically fragmented and then hybridized to the genome chip arrays. These arrays were detected and analyzed using Applied Biosystems Chemiluminescence Detection kit and 1700 Chemiluminescent Microarray Analyzer (Macrogen). The quality, yield and size distribution of total RNA, labeled transcripts and fragmented cRNA were estimated using this analyzer.

We then carried out a hierarchical cluster analysis based on the differentially expressed genes in at least one comparison between high-grade OD vs. low-grade OD, or high-grade OD vs. normal white matter, or low-grade OD vs. normal white matter ( $\mathrm{a}>2$-fold difference). Among them, overexpressed genes with a $>+2$-fold difference, in comparison of both high-grade ODs vs. normal white matter and low-grade ODs vs. normal white matter, were selected and functionally classified using the PANTHER classification system (http://www.pantherdb.org). The 20 most highly expressed genes compared with normal white matter in low-grade OD and in high-grade OD, in each case, were investigated. Avadis Prophetic version.3.3 (Strand Genomics, Bangalore, India) was used in a statistical analysis.

Reverse transcription-PCR (RT-PCR) and real-time PCR. Total RNA was extracted by TRIzol (Sigma, St. Louis, MO) following the manufacturer's protocol. The first cDNA strand was synthesized using $1 \mu \mathrm{g}$ total RNA. Real-time PCR was carried out to detect PCR products, using the Light Cycler System (Roche, Mannheim, Germany) and the DNAbinding dye Syber-Green I (Roche). The PCR was set up using $100 \mathrm{pmol} / \mathrm{l}$ of each primer for StAR, P450scc and 3ßHSD. The conditions were as following: for StAR (251 bp), 40 cycles; annealing temperature $57^{\circ} \mathrm{C}$; forward primer 5'-GGAAGCCTGCAAGTCTAAGATCTC-3' and reverse primer 5'-TCTGGTGACAGTGGGATGGGTGGG-3', for P450scc (182 bp), 40 cycles; annealing temperature $50^{\circ} \mathrm{C}$; forward primer 5'-GCTCAGCAAAGACAAGAACA-3' and reverse primer 5'-GAATGAGGTTGAATGTGG TG-3', for 3ß-HSD (181 bp), 35 cycles; annealing temperature $54^{\circ} \mathrm{C}$; forward primer 5'-ATCCACACCGCCTGTATCAT-3' and reverse primer 5'-TCTGGATGATTTCCTTGTAGGAG-3', for GAPDH (343 bp), 25 cycles; annealing temperature $60^{\circ} \mathrm{C}$; forward primer 5'-TGAACGGGAAGCTCACTGG-3' and reverse primer 5'-TCCACCACCCTGTTGCTGTA-3'.

The fluorescence intensity of the double-strand-specific Syber-Green I, which reflects the amount of the specific PCR products formed for GAPDH, was read by Light Cycler at $88^{\circ} \mathrm{C}$ at the end of each extension process. After PCR, the products were resolved on a $2 \%$ agarose ethidium bromide gel. Images were captured with Polaroid film under UV light. The CT (cycle threshold)-value was the cycle number at which the fluorescence generated within a reaction crossed the threshold within the linear phase of the amplification profile. The amplification plots and CT-values were exported from the exponential phase of PCR directly onto a Microsoft Excel worksheet for further analysis. The mRNA transcript level was normalized against GAPDH at each sample. The standard curve was the normalized mRNA transcript level plotted against the log-value of the input cDNA concentration at each sample. To compare GAPDH and StAR, relative quantification was performed. The comparative CT method was used. Briefly, this comparative CT method involved averaging triplicate samples taken as the CT-values for StAR and GAPDH. The $\triangle \mathrm{CT}$-value was obtained by subtracting the average GAPDH CT-value from the average CT-value of StAR. The average $\triangle \mathrm{CT}$ of one control subject (LOD-1) was used as the calibrator. The fold change was calculated according to the formula $2-(\Delta \Delta \mathrm{CT})$, where $\Delta \Delta \mathrm{CT}$ was the difference between $\Delta \mathrm{CT}$ and the $\Delta \mathrm{CT}$ calibrator value.

In situ detection of StAR protein by immunofluorescent study. To confirm StAR protein in human brain tissue, we performed immunofluorescent staining on normal and OD samples. Each sample was washed once with PBS and immersed in $4 \%$ formaldehyde. The fixed tissue was washed with PBS and immersed in $1 \%$ Triton X-100 in PBS for 10 min. After 
Table I. 1p/19q deletion in 10 low-grade and 10 high-grade oligodendrogliomas.

\begin{tabular}{|c|c|c|c|}
\hline Pathological type and number ${ }^{a}$ & Gender/age (years) & Follow-up (months) & $1 \mathrm{p}$ deletion $/ 19 \mathrm{q}$ deletion ${ }^{\mathrm{b}}$ \\
\hline LOD-1 & $\mathrm{F} / 31$ & 40 & $\mathrm{ND} / \mathrm{ND}$ \\
\hline LOD-2 & $\mathrm{M} / 33$ & 6 & $-/-$ \\
\hline LOD-3 & $\mathrm{F} / 46$ & 25 & $+/-$ \\
\hline LOD-4 & $\mathrm{M} / 26$ month & 41 & $-/-$ \\
\hline LOD-5 & $\mathrm{F} / 11$ & 19 & $-/-$ \\
\hline LOD-6 & $\mathrm{M} / 37$ & 20 & $+/+$ \\
\hline LOD-7 & $\mathrm{M} / 32$ & 50 & $+/+$ \\
\hline LOD-8 & $\mathrm{F} / 67$ & 21 & $+/+$ \\
\hline LOD-9 & $\mathrm{M} / 46$ & 50 & $+/+$ \\
\hline LOD-10 & $\mathrm{M} / 32$ & 36 & $+/+$ \\
\hline HOD-1 & $\mathrm{M} / 47$ & 32 & $+/ \mathrm{ND}$ \\
\hline HOD-2 & $\mathrm{F} / 62$ & 8 (expired) & $-/+$ \\
\hline HOD-3 & $\mathrm{F} / 31$ & 61 & $-/-$ \\
\hline HOD-4 & $\mathrm{F} / 56$ & 32 & $+/+$ \\
\hline HOD-5 & $\mathrm{F} / 56$ & 29 & $+/+$ \\
\hline HOD-6 & $\mathrm{M} / 33$ & 45 & ND/ND \\
\hline HOD-7 & $\mathrm{M} / 46$ & 36 & $+/+$ \\
\hline HOD-8 & $\mathrm{M} / 37$ & 22 & $+/+$ \\
\hline HOD-9 & $\mathrm{M} / 48$ & 27 & $+/+$ \\
\hline HOD-10 & $\mathrm{M} / 28$ & 21 & $+/+$ \\
\hline
\end{tabular}

${ }^{a} \mathrm{HOD}$, high-grade oligodendroglioma; LOD, low-grade olidodendroglioma. ${ }^{\mathrm{b}}+$, Deletion was observed; -, deletion was not observed and ND, not done.

washing with PBS, each cover slip was blocked with $3 \%$ BSA in PBS for $10 \mathrm{~min}$ and then incubated for $1 \mathrm{~h}$ with a 1:250 dilution of anti-StAR antibody (rabbit anti-human polyclonal antibody (Santa Cruz Biotechnologies, Santa Cruz, CA). Each cover slip was then washed three times with $1 \%$ BSA and incubated for $1 \mathrm{~h}$ with a 1:250 dilution of a secondary antibody (horseradish peroxidase-conjugated donkey antirabbit antibody (Amersham Pharmacia Biotech, Amersham, UK). Thereafter, counterstaining of the nucleus was performed using $0.001 \%$ of DAPI in PBS. The tissue was then examined by fluorescence microscopy.

Statistical analysis. The software SPSS (version 11.0, SPSS Inc., Chicago, IL) was used. Quantitative PCR data between two groups were compared using a Mann-Whitney test. Nonparametric correlation using Kendall's tau-b was applied to investigate the correlation of RT-PCR data. A p-value of $<0.05$ was deemed statistically significant.

\section{Results}

Gene expression microarray. Hierarchical clustering for the differentially expressed 6800 genes of $>2$-fold difference in at least one comparison of high-grade ODs vs. low-grade ODs, or high-grade ODs vs. normal white matter, or low-grade ODs vs. normal white matter is demonstrated in Fig. 1.

Clustering by similarity of expression profiles revealed that the samples were inclined to aggregate in clusters such as low-grade OD and normal white matter vs. high-grade OD, with some exceptions (LOD-3 and HOD-5) (Fig. 1).
The top 20 among the 714 overexpressed genes of $>+2$-fold difference, in comparing low-grade ODs and high-grade ODs with normal white matter, respectively, are shown in Tables II and III. The functional characteristics of overexpressed genes in low-grade OD were shown to be the following: related to developmental process (BMP2, LMNA, DLL3, HES6, IRX3, AMH, ASCL1 and DLL1), metabolism of amino acid (MTHFD2), lipid and steroid (LCAT), nucleic acid (MYT1, HIST1H1E, LIMD1), blood circulatory homeostasis (NPPA), synaptic transmission (GRIA4), protein modification such as proteolysis or cell communication (TIMP4, CPXM and DDR1) and immunity (C1QTNF5). Most of the above genes revealed that expression was relatively decreased or similar in high-grade ODs compared with in low-grade ODs.

In high-grade $\mathrm{OD}$, the overexpressed genes were related to the cell cycle (CDC2, KIFC1, CCND1 and TPX2), nucleic acid metabolism such as DNA or mRNA synthesis (TOP2A, MXD3 and SF3B4), DNA repair (APEX2), cell structure and motility (KIF14, KIF4A and DBNL) and phosphorylation of protein (MELK and PBK). In contrast to low-grade ODs, as the grade of the tumor increased, the changes became exaggerated.

Even though most of the genes related to steroidogenesis were not included in the high-rank list, we investigated this expression in ODs (Table IV). The expression of LCAT, DGKB, CYP4V2, AKR1C3, PLTP, ABCA1, STARD10 and PCTP showed a decreasing or mildly increasing tendency in high-grade ODs compared with low-grade ODs, similarly to the genes in Table II. 
Table II. The 20 most highly expressed genes in low-grade oligodendrogliomas compared with normal white matter.

\begin{tabular}{|c|c|c|c|c|c|c|}
\hline Gene & GenBank & Gene name & Function & Fold $(\mathrm{L} / \mathrm{N})^{\mathrm{a}}$ & Fold $(\mathrm{H} / \mathrm{N})^{\mathrm{a}}$ & Fold $(\mathrm{H} / \mathrm{L})^{\mathrm{a}}$ \\
\hline BMP2 & NM_001200 & $\begin{array}{l}\text { Bone morphogenetic } \\
\text { protein } 2\end{array}$ & $\begin{array}{l}\text { Skeletal } \\
\text { development }\end{array}$ & 32.15 & 11.49 & -2.80 \\
\hline MTHFD2 & NM_006636 & $\begin{array}{l}\text { Methenyltetrahydrofolate } \\
\text { cyclohydrolase }\end{array}$ & $\begin{array}{l}\text { Amino acid } \\
\text { metabolism }\end{array}$ & 12.48 & 6.24 & -2.00 \\
\hline LMNA & NM_005572 & Lamin $\mathrm{A} / \mathrm{C}$ & Cytoskeletal protein & 11.80 & 17.45 & 1.48 \\
\hline NPPA & NM_006172 & $\begin{array}{l}\text { Natriuretic peptide } \\
\text { precursor A }\end{array}$ & $\begin{array}{l}\text { Blood circulatory } \\
\text { homeostasis }\end{array}$ & 11.69 & 6.91 & -1.69 \\
\hline GRIA4 & NM_000829 & $\begin{array}{l}\text { Glutamate receptor, } \\
\text { ionotrophic, AMPA } 4\end{array}$ & Synaptic transmission & 10.80 & 5.19 & -2.08 \\
\hline DLL3 & NM_016941 & $\delta$-like 3 & $\begin{array}{l}\text { Nucleic acid metabolism } \\
\text { (neurogenesis) }\end{array}$ & 10.61 & 4.35 & -2.44 \\
\hline HES6 & NM_018645 & Hairy and enhancer of split 6 & $\begin{array}{l}\text { Nucleic acid metabolism } \\
\text { (neurogenesis) }\end{array}$ & 10.49 & 8.59 & -1.22 \\
\hline TIMP4 & NM_003256 & $\begin{array}{l}\text { TIMP metallopeptidase } \\
\text { inhibitor } 4\end{array}$ & $\begin{array}{l}\text { Protein metabolism } \\
\text { (proteolysis) }\end{array}$ & 10.31 & 3.87 & -2.66 \\
\hline CHST9 & NM_031422 & $\begin{array}{l}\text { Carbohydrate } \\
\text { (N-acetylgalactosamine 4-0) } \\
\text { sulfotransferase } 9\end{array}$ & Sulfur metabolism & 10.30 & 4.20 & -2.45 \\
\hline CPXM & NM_019609 & Carboxypeptidase $\mathrm{X}$ & $\begin{array}{l}\text { Protein metabolism } \\
\text { (proteolysis) }\end{array}$ & 10.23 & 15.79 & 1.54 \\
\hline IRX3 & NM_024336 & $\begin{array}{l}\text { Iroquois homeobox } \\
\text { protein } 3\end{array}$ & $\begin{array}{l}\text { Nucleic acid metabolism } \\
\text { (neurogenesis) }\end{array}$ & 8.95 & 3.20 & -2.80 \\
\hline LCAT & NM_000229.1 & $\begin{array}{l}\text { Lecithin-cholesterol } \\
\text { acyltransferase }\end{array}$ & $\begin{array}{l}\text { Lipid, fatty acid and } \\
\text { steroid metabolism }\end{array}$ & 8.64 & 8.89 & 1.03 \\
\hline $\mathrm{AMH}$ & NM_000479 & Anti-Mullerian hormone & Mesoderm development & 8.25 & 4.38 & -1.88 \\
\hline C1QTNF5 & NM_015645.1 & $\begin{array}{l}\mathrm{C} 1 \mathrm{q} \text { and tumor necrosis } \\
\text { factor-related protein } 5\end{array}$ & $\begin{array}{l}\text { Complement-mediated } \\
\text { immunity }\end{array}$ & 8.12 & 4.53 & -1.79 \\
\hline MYT1 & NM_004535.2 & Myelin transcription factor 1 & $\begin{array}{l}\text { Nucleic acid metabolism } \\
\text { (mRNA transcription } \\
\text { regulation) }\end{array}$ & 7.48 & 2.90 & -2.58 \\
\hline HIST1H1E & NM_005321 & Histone $1, \mathrm{H} 1 \mathrm{e}$ & $\begin{array}{l}\text { Nucleic acid metabolism } \\
\text { (chromatin packaging } \\
\text { and remodeling) }\end{array}$ & 7.45 & 2.69 & -2.76 \\
\hline ASCL1 & NM_004316 & Achaete-scute complex-like 1 & $\begin{array}{l}\text { Nucleic acid metabolism } \\
\text { (neurogenesis) }\end{array}$ & 7.38 & 3.49 & -2.11 \\
\hline DLL1 & NM_005618 & $\delta$-like 1 & $\begin{array}{l}\text { Nucleic acid metabolism } \\
\text { (neurogenesis) }\end{array}$ & 7.16 & 2.51 & -2.85 \\
\hline DDR1 & NM_013994 & $\begin{array}{l}\text { Discoidin domain } \\
\text { receptor family, member } 1\end{array}$ & $\begin{array}{l}\text { Protein modification } \\
\text { (cell communication) }\end{array}$ & 7.15 & 6.55 & -1.09 \\
\hline LIMD1 & NM_014240 & LIM domains containing 1 & $\begin{array}{l}\text { Nucleic acid metabolism } \\
\text { (mRNA transcription } \\
\text { regulation) }\end{array}$ & 6.77 & 10.82 & 1.60 \\
\hline
\end{tabular}

${ }^{\mathrm{a}} \mathrm{H}$, high-grade OD; L, low-grade OD and N, normal white matter.

The data of genes with markedly decreased expression in high-grade and low-grade ODs relative to normal white matter are not shown.
Expression of StAR, P450scc and 3ß-HSD. The presence of mRNA for StAR, P450scc and 3B-HSD in tumor tissue was determined by RT-PCR. StAR and P450scc each were 




Figure 1. Gene expression microarray. Hierarchical clustering of the samples based on 6800 genes [ $>2$-fold difference in at least one comparison between high grade oligodendrogliomas (ODs) vs. low-grade ODs, or high-grade ODs vs. normal white matter, or low-grade ODs vs. normal white matter] showing the pattern of aggregation in clusters such as low-grade OD and normal white matter vs. high-grade OD, with some exceptions (LOD-3 and HOD-5). HOD, high grade oligodendroglioma and LOD, low grade oligodendroglioma.
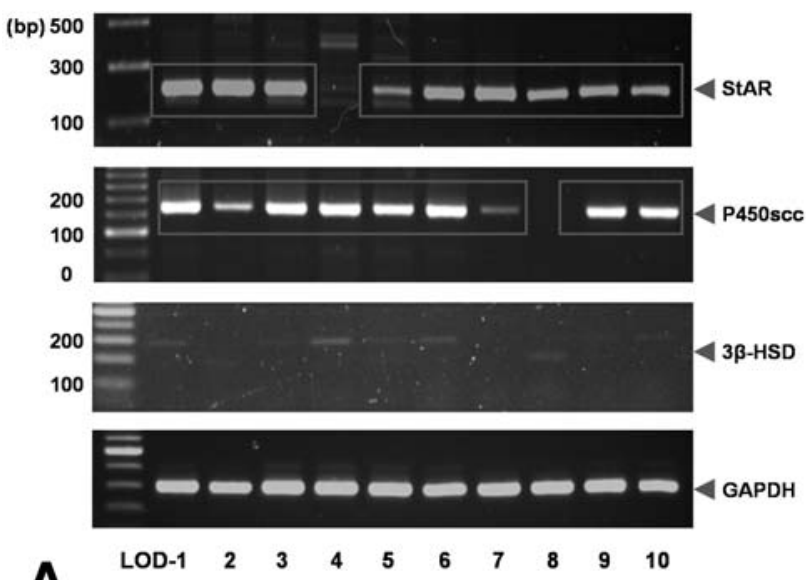

A

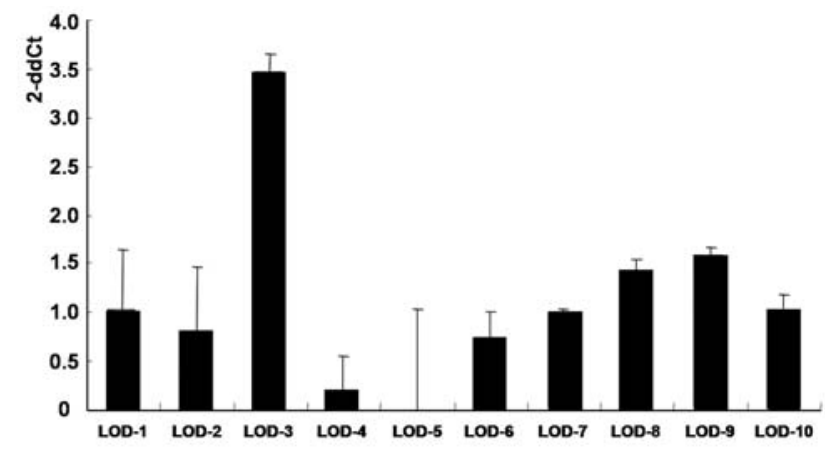

C (bp)
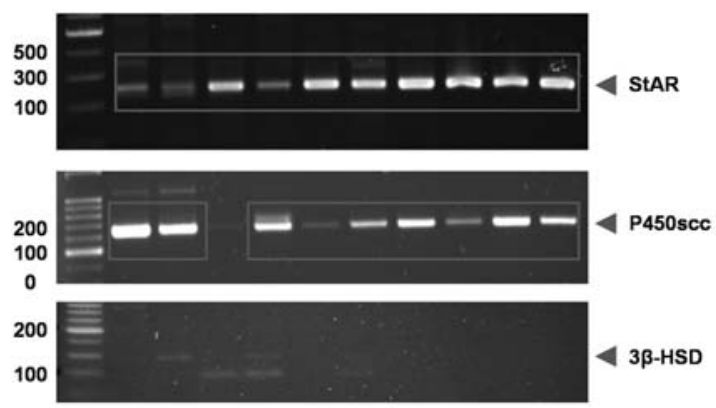

B

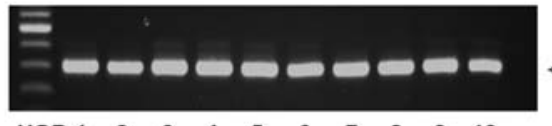

1 GAPDH

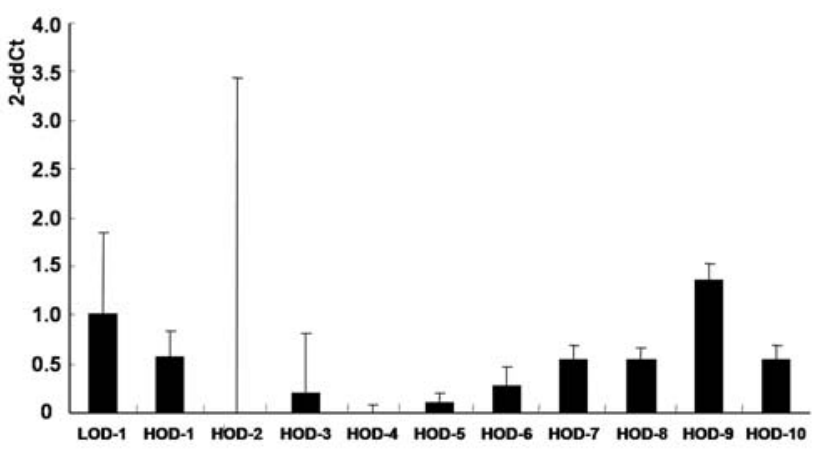

D

Figure 2. RT-PCR for StAR, P450scc and 3ß-HSD (A and B) and real-time PCR analysis for StAR (C and D). (A) In low-grade oligodendrogliomas (ODs), StAR was detected in 9 cases. The P450scc expression was positive in 9 low-grade ODs (90\%). Nonetheless, 3B-HSD was not expressed in any of the samples. The lowest panel shows GAPDH mRNA expression as a procedural internal control and mRNA intactness. (B) In high-grade ODs, StAR was detected in all of the cases. The P450scc expression was positive in 9 high-grade ODs (90\%). However, 3B-HSD was not expressed in any of the samples. The mRNA fold changes of StAR in low-grade OD (C) and high-grade OD (D) showing more increased regulation for StAR mRNA in the former than in the latter ( $\mathrm{p}=0.023$ ). 
Table III. The 20 most highly expressed genes in high-grade oligodendrogliomas compared with normal white matter.

\begin{tabular}{|c|c|c|c|c|c|c|}
\hline Gene & GenBank & Gene name & Function & Fold $(\mathrm{L} / \mathrm{N})^{\mathrm{a}}$ & Fold $(\mathrm{H} / \mathrm{N})^{\mathrm{a}}$ & Fold $(\mathrm{H} / \mathrm{L})^{\mathrm{a}}$ \\
\hline $\mathrm{CDC} 2$ & NM_001786 & Cell division cycle 2 & Cell cycle & 5.11 & 26.80 & 5.25 \\
\hline KIFC1 & NM_002263 & Kinesin family member $\mathrm{C} 1$ & Cell cycle & 3.84 & 20.87 & 5.43 \\
\hline TOP2A & NM_001067 & Topoisomerase (DNA) II $\alpha$ & $\begin{array}{l}\text { Nucleic acid metabolism } \\
\text { (DNA replication) }\end{array}$ & 3.19 & 19.24 & 6.04 \\
\hline KIF14 & NM_014875 & Kinesin family member 14 & Cell structure and motility & 2.91 & 18.67 & 6.42 \\
\hline MELK & NM_014791 & $\begin{array}{l}\text { Maternal embryonic leucine } \\
\text { zipper kinase }\end{array}$ & $\begin{array}{l}\text { Protein modification } \\
\text { (phosphorylation) }\end{array}$ & 2.31 & 18.48 & 8.00 \\
\hline LMNA & NM_005572 & Lamin $\mathrm{A} / \mathrm{C}$ & Cytoskeletal protein & 11.80 & 17.45 & 1.48 \\
\hline CCND1 & IM_053056 & Cyclin D1 & Cell cycle & 2.18 & 17.08 & 7.83 \\
\hline CPXM & NM_019609 & Carboxypeptidase X & $\begin{array}{l}\text { Protein metabolism } \\
\text { (proteolysis) }\end{array}$ & 10.23 & 15.79 & 1.54 \\
\hline TNNT1 & NM_003283 & Troponin T type 1 & Cytoskeletal protein & 3.85 & 14.68 & 3.81 \\
\hline PBK & NM_018492 & PDZ binding kinase & $\begin{array}{l}\text { Protein metabolism } \\
\text { (phosphorylation) }\end{array}$ & 2.61 & 12.54 & 4.80 \\
\hline TPX2 & NM_012112 & $\begin{array}{l}\text { TPX2, microtubule- } \\
\text { associated, homolog }\end{array}$ & Cell cycle & 2.70 & 12.34 & 4.57 \\
\hline BMP4 & NM_001202 & $\begin{array}{l}\text { Bone morphogenetic } \\
\text { protein } 4\end{array}$ & Skeletal development & 2.62 & 10.93 & 4.17 \\
\hline LIMD1 & NM_014240 & LIM domains containing 1 & $\begin{array}{l}\text { Nucleic acid metabolism } \\
\text { (mRNA transcription } \\
\text { regulation) }\end{array}$ & 6.77 & 10.82 & 1.60 \\
\hline KIF4A & NM_012310 & Kinesin family member 4A & Cell structure and motility & 2.17 & 10.67 & 4.91 \\
\hline TP53 & NM_000546 & Tumor protein $\mathrm{p} 53$ & Cellular tumor antigen & 4.11 & 9.90 & 2.41 \\
\hline DBNL & NM_001014436 & Drebrin-like & Cell structure and motility & 5.61 & 9.73 & 1.73 \\
\hline MXD3 & NM_031300.2 & MAX dimerization protein 3 & $\begin{array}{l}\text { Nucleic acid metabolism } \\
\text { (mRNA transcription } \\
\text { regulation) }\end{array}$ & 3.65 & 9.08 & 2.49 \\
\hline APEX2 & NM_014481 & $\begin{array}{l}\text { Apurinic/apyrimidinic } \\
\text { endonuclease } 2\end{array}$ & $\begin{array}{l}\text { Nucleic acid metabolism } \\
\text { (DNA repair) }\end{array}$ & 6.06 & 9.02 & 1.49 \\
\hline LCAT & NM_000229.1 & $\begin{array}{l}\text { Lecithin-cholesterol } \\
\text { acyltransferase }\end{array}$ & $\begin{array}{l}\text { Lipid, fatty acid and } \\
\text { steroid metabolism }\end{array}$ & 8.64 & 8.89 & 1.03 \\
\hline SF3B4 & NM_005850 & $\begin{array}{l}\text { Cplicing factor } 3 b \text {, } \\
\text { subunit } 4\end{array}$ & $\begin{array}{l}\text { Nucleic acid metabolism } \\
\text { (mRNA splicing) }\end{array}$ & 5.42 & 8.80 & 1.63 \\
\hline
\end{tabular}

${ }^{\text {a }} \mathrm{H}$, high-grade OD; L, low-grade OD and N, normal white matter.

expressed in all low-grade ODs, with one exception: StAR mRNA was not expressed in LOD-4 and P450scc mRNA was not detected in LOD-8. 3ß-HSD was not expressed in any case (Fig. 2A). Similarly, in high-grade ODs, StAR was expressed in all the cases and $\mathrm{P} 450$ scc was expressed in all of the cases except HOD-3. 3ß-HSD, again, was not expressed in any of the cases (Fig. 2B).

Real-time PCR for StAR. This study was a semi-quantitative method in that LOD-1 was used as a calibrator to determine the relative CT-value or fold changes. The present results revealed that CT-values are higher in high-grade OD cases for
StAR, suggesting that StAR mRNA expression is relatively down-regulated in high-grade OD, compared with low-grade $\mathrm{OD}(\mathrm{p}=0.023$ ). Table $\mathrm{V}$, Fig. $2 \mathrm{C}$ and $\mathrm{D}$ show the $\mathrm{CT}$ values for GAPDH and StAR with the fold changes.

Immunofluorescent staining for StAR protein. In the normal brain, no cell possessing a StAR-positive signal was observed except in a few endothelial cells. In a high-grade OD (HOD-5), few tumor cells are StAR-positive. However, in low-grade ODs (LOD-3 and 8), the StAR-positive signal was much stronger and more abundant than in the normal brain or the high-grade ODs (Fig. 3). 
Table IV. Highly expressed genes of $>2$-fold difference related to steroidogenesis.

\begin{tabular}{|c|c|c|c|c|c|c|}
\hline Gene & GenBank & Gene name & Function & Fold $(\mathrm{L} / \mathrm{N})^{\mathrm{a}}$ & Fold $(\mathrm{H} / \mathrm{N})^{\mathrm{a}}$ & Fold $(\mathrm{H} / \mathrm{L})^{\mathrm{a}}$ \\
\hline LCAT & NM_000229.1 & $\begin{array}{l}\text { Lecithin-cholesterol } \\
\text { acyltransferase }\end{array}$ & $\begin{array}{l}\text { Extracellular } \\
\text { cholesterol } \\
\text { metabolism }\end{array}$ & 8.64 & 8.89 & 1.03 \\
\hline DGKB & NM_145695 & Diacylglycerol kinase, $\beta$ & $\begin{array}{l}\text { Lipid metabolism } \\
\text { (intracellular } \\
\text { signaling cascade) }\end{array}$ & 3.92 & 3.40 & -1.15 \\
\hline CYP4V2 & NM_207352 & $\begin{array}{l}\text { Cytochrome P450, family } 4 \text {, } \\
\text { subfamily V, polypeptide }\end{array}$ & Steroid metabolism & 22.98 & 2.86 & -1.04 \\
\hline AKR1C3 & NM_003739 & $\begin{array}{l}\text { 3- } \alpha \text { hydroxysteroid } \\
\text { dehydrogenase, type I }\end{array}$ & Steroid metabolism & 2.98 & 2.79 & -1.07 \\
\hline C7orf10 & NM_024728 & $\begin{array}{l}\text { Chromosome } 7 \text { open reading } \\
\text { frame } 10\end{array}$ & Steroid metabolism & 2.91 & 7.51 & 2.58 \\
\hline PLTP & NM_182676 & Phospholipid transfer protein & Lipid transport & 2.56 & 2.19 & -1.01 \\
\hline ST6GALNAC4 & NM_175039 & $\begin{array}{l}\text { ST6 ( } \alpha \text {-N-acetyl-neuraminyl } \\
-2,3-\beta \text {-galactosyl-1,3)-N- } \\
\text { acetylgalactosaminide } \\
\alpha-2,6 \text {-sialyltransferase } 4\end{array}$ & $\begin{array}{l}\text { Glycolipid } \\
\text { metabolism }\end{array}$ & 2.35 & 5.40 & 2.29 \\
\hline ABCA1 & NM_005502 & $\begin{array}{l}\text { ATP-binding cassette, } \\
\text { sub-family A (ABC1), } \\
\text { member } 1\end{array}$ & Sterol transport & 2.34 & 2.56 & 1.09 \\
\hline STARD10 & NM_006645 & START domain containing 10 & $\begin{array}{l}\text { Cholesterol } \\
\text { transport }\end{array}$ & 2.25 & 2.36 & 1.05 \\
\hline PCTP & NM_021213 & $\begin{array}{l}\text { Phosphatidylcholine transfer } \\
\text { protein }\end{array}$ & Lipid transport & 2.17 & 2.14 & -1.01 \\
\hline
\end{tabular}

${ }^{\mathrm{a}} \mathrm{H}$, high-grade OD; L, low-grade OD and N, normal white matter.

Table V. Cycle-threshold (CT) values and mRNA fold changes of StAR in oligodendrogliomas.

\begin{tabular}{|c|c|c|c|c|c|}
\hline Samples & Average CT for StAR & GAPDH & $\Delta \mathrm{CT}$ & $\Delta \Delta \mathrm{Ct}$ & 2-ddCt \\
\hline LOD-1 (calibrator) & 30.53 & 21.34 & 9.18 & 0 & 1 \\
\hline LOD-2 & 32.34 & 22.79 & 9.55 & 0.36 & 0.77 \\
\hline LOD-3 & 30.90 & 23.50 & 7.39 & -1.78 & 3.45 \\
\hline LOD-4 & 35.51 & 23.80 & 11.70 & 2.52 & 0.17 \\
\hline LOD-5 & 35.98 & 20.06 & 15.92 & 6.73 & 0.01 \\
\hline LOD-6 & 32.31 & 22.60 & 9.70 & 0.52 & 0.69 \\
\hline LOD-7 & 30.19 & 20.99 & 9.20 & 0.02 & 0.98 \\
\hline LOD-8 & 29.09 & 20.41 & 8.68 & -0.50 & 1.41 \\
\hline LOD-9 & 29.88 & 21.34 & 8.54 & -0.64 & 1.56 \\
\hline LOD-10 & 30.97 & 21.8 & 9.17 & -0.01 & 1.01 \\
\hline HOD-1 & 34.25 & 24.82 & 9.43 & 0.84 & 0.55 \\
\hline HOD-2 & 38.11 & 21.62 & 16.49 & 7.9 & 0.00419 \\
\hline HOD-3 & 33.28 & 22.28 & 11.00 & 2.41 & 0.18 \\
\hline HOD-4 & 34.02 & 18.69 & 15.33 & 6.74 & 0.01 \\
\hline HOD-5 & 33.04 & 20.91 & 12.12 & 3.53 & 0.08 \\
\hline HOD-6 & 32.54 & 22.05 & 10.49 & 1.9 & 0.26 \\
\hline HOD-7 & 29.7 & 20.19 & 9.50 & 0.91 & 0.53 \\
\hline HOD-8 & 30.40 & 21.81 & 9.42 & 0.84 & 0.55 \\
\hline HOD-9 & 31.86 & 23.72 & 8.14 & -0.44 & 1.35 \\
\hline
\end{tabular}



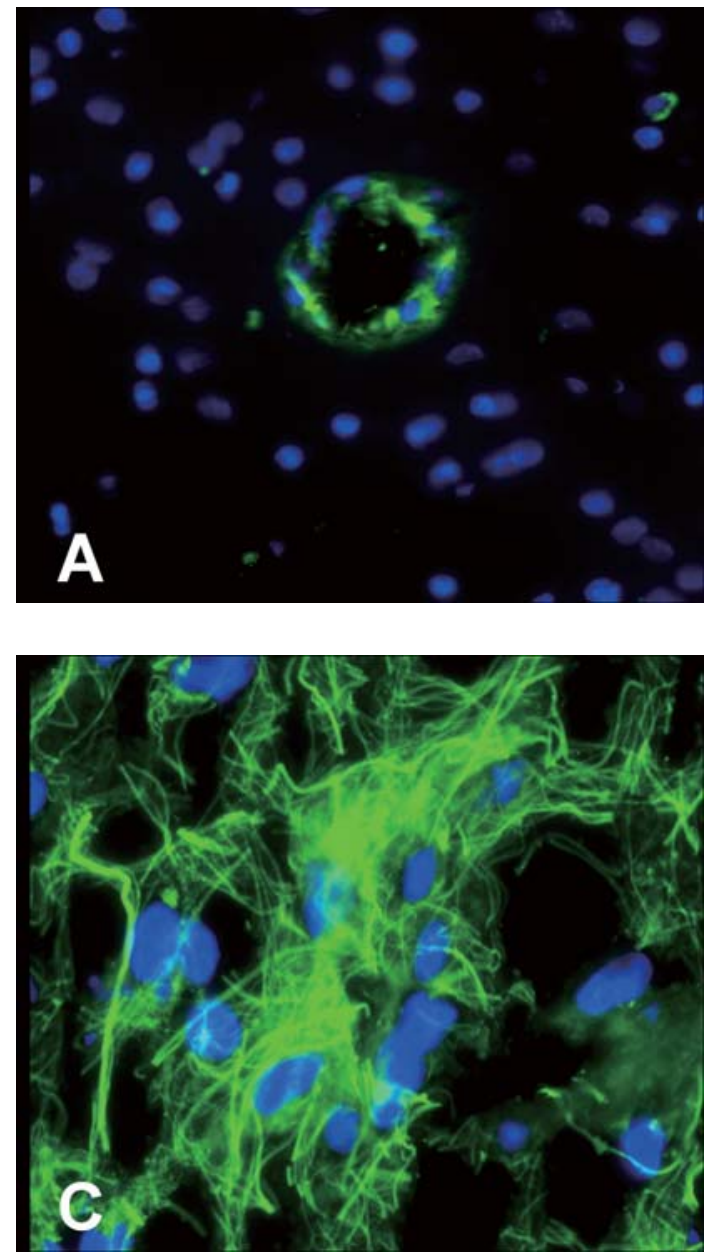
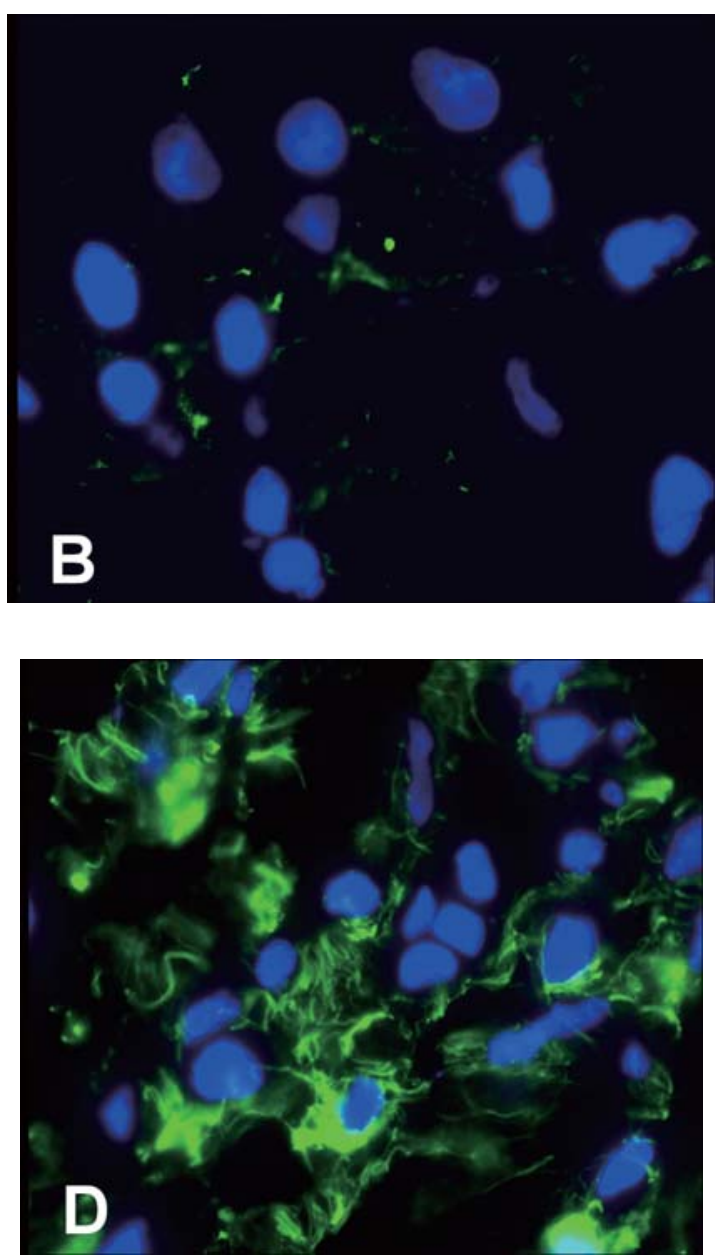

Figure 3. Immunofluorescent staining in normal brain, low-grade oligodendrogliomas (ODs) and high-grade ODs. (A) In the normal brain, only endothelial cells were StAR-positive (green) (x200). The DAPI-positive signal (blue) indicates a cell nucleus. (B) In HOD-5, few tumor cells are StAR-positive (x1000). (C and D) In the LOD-3 (x1000) and LOD-8 (x1000), respectively, the StAR-positive signal is much stronger and more abundant than in the normal brain and HOD-5. HOD, high grade oligodendroglioma and LOD, low grade oligodendroglioma.

\section{Discussion}

Gene expression profiling in ODs. In our series, although the number of samples was small, they showed a tendency to cluster with a group of low-grade OD and normal white matter and with another group of high-grade OD. LOD-3 and HOD-5 showed somewhat different clustering patterns from those of the other samples and thus we carefully reviewed their pathological slides. In the case of HOD-5, a heterogeneous appearance showing the characteristics of both low- and high-grade ODs was observed. Such a different pattern might be due to the heterogeneity. Nonetheless, LOD-3 was a usual low-grade OD, pathologically.

Similar to the findings of other studies, the genes involved in cell cycle, DNA replication, migration (cell structure and motility), protein modification including phosphorylation and signal transduction became up-regulated as the grade increased. However, in low-grade ODs, the functional characteristics of highly overexpressed genes differed. The following process was involved: normal development of neuron, bone, mesoderm and cytoskeleton; metabolism including amino acid, steroid, synapsis, and circulation; regulation of mRNA transcription and remodeling of chromatin; cell-to-cell communication; immunity. Remarkably, expression of the above genes was relatively decreased or similar in high-grade ODs. Thus, through these data, we established that there was a difference in genetic expression between low- and high-grade ODs.

The most important finding was that many genes involved in lipid or steroid metabolism, including LCAT, DGKB, CYP4V2, AKR1C3, PLTP, ABCA1, STARD10, and PCTP, were highly expressed in ODs compared with normal white matter. No study of gene expression microarray focusing on genes of steroid synthesis, that is, no study similar to ours, can be found in the literature. Most notably, the present study revealed that expression of genes related to steroid synthesis was more elevated in low-grade ODs than in the normal brain. Nonetheless, expression of the same genes tended to be rather diminished or similar in high-grade ODs compared with low-grade ODs.

Among the highly expressed genes in low-grade OD (Table II), BMP2 (12), DLL3 (13), HES6, ASCL1 (14), TIMP4 (15) and DDR1 (16) might be considered possible targets in the growth control of OD, because several studies have suggested that overexpression of these genes can accelerate growth or proliferation of several brain tumors including gliomas. Nonetheless, there is as yet no study revealing genetic expression in ODs or its exaggeration in low-grade ODs. 
StAR and neurosteroids in ODs. Under normal conditions, neurosteroids are associated with a range of physiological actions including neurotransmission via specific receptors. They are involved in neural growth, differentiation and plasticity. Neurosteroids are synthesized in specialized regions of the brain and multiple factors are related. Transportation of cholesterol from the cytoplasm into the mitochondrial inner membrane must precede steroidogenesis. StAR protein is essential for an initial and rate-limiting step in steroid biosynthesis and transfer of cholesterol to the inner mitochondrial membrane. StAR is related to physiological and pathological conditions as a crucial protein in neurosteroidogenesis (17-19).

Steroid receptors are present in human brain tumors and neurosteroidogenesis also occurs de novo (20). Intratumoral production and/or metabolism of biologically active steroid hormones have been considered to play important roles in the development and biological behavior of brain tumors. In addition, cholesterol is necessary for proliferation of glioma cells (18). Dexamethasone, a glucocorticoid agonist, stimulates the proliferation of human glioma cells, whereas RU38486, a steroid hormone antagonist, inhibits the growth of a human malignant glioma cell line $(21,22)$. These results suggest that steroid hormones influence the proliferation of brain tumors via specific receptors. Even if steroid hormones are supplied through microvessels surrounding the tumor, it is possible that de novo steroidogenesis locally supplies steroid hormones for proliferative tumoral tissue. In fact, the metabolism of steroid hormones in human astrocytoma has been partially revealed (23). Besides, there are a few studies that the percentage expressing progesterone receptor is higher in high-grade astrocytomas than in low-grade tumors $(20,24)$. In addition, Kim et al $(17,25)$ previously demonstrated several important results. First, StAR mRNA expression is considerably low in normal white matter, compared with in normal gray matter. Second, StAR-immunoreactivity is much stronger and more abundant in glial tumors including OD than in normal white matter. Third, StAR-positive cells are GFAP-positive tumor cells in gliomas, whereas they are neurons or glial cells in normal gray matter, according to immunohistochemical studies. Fourth, StAR expression is greater in glioblastomas than in anaplastic astrocytomas. All of these findings suggest that the increase of StAR mRNA might be correlated with tumor progression and intratumoral steroidogenesis in malignant astrocytoma and that the StAR pathway might be a juxtacrine/autocrine loop involving proliferation or progression in OD as well as other glial tumors. Immunohistochemistry for StAR and P450scc revealed the expression of the two proteins in multiple brain regions, including the cerebellum, pons, cerebral cortex and hypothalamus. In addition, they were confirmed to co-localize in the mitochondria of the some cortex, hippocampus and cerebellum (26). Furthermore, StARpositive cells were also detected in gliomas as well as in the normal brain and their frequency and density were higher in glioma tissue (17).

Even if several studies have confirmed the existence of StAR and/or P450scc in various cortical areas of the brain, there are few studies focusing on the relation of glioma and StAR expression. Initially, we expected more elevated expression of StAR in high-grade ODs than in low-grade ODs.
However, we obtained previously described data showing a more up-regulated real-time PCR of StAR in low-grade ODs. In addition, through the gene expression array, we could derive a different hypothesis from those of other studies that had suggested the relation of StAR expression to tumor grade. Our results reveal that the neurosteroidogenic mechanism based on StAR can have different effects on low-grade OD and high-grade OD: as the grade of OD increases, the juxtacrine/autocrine proliferative effect of StAR decreases.

In the present study, StAR was detected in brain tumors of white matter origin such as ODs. It is interesting that white matter-originated gliomas show strong StAR signals, because there is only a small amount in normal white matter. In addition, considering the above results of gene expression array and real-time PCR, this gene might serve as a promising reference in understanding the molecular characteristics of low- and high-grade OD. The authors assume that in OD, as the grade is higher, the 'escape' mechanism over the StAR pathway in tumor growth is more distinct. The hypothesis is that the cell-proliferative or preserving effect by the StARrelated system is more important in low-grade OD than in the high-grade type, because the system of de novo steroidogenesis in low-grade OD is nearly intact, as in normal oligodendrocytes. In addition, in situ detection of StAR protein by immunofluorescent study showed more abundant staining in low-grade ODs than in high-grade ODs. These findings could provide supplementary evidence of the above hypothesis. However, further study is mandatory, because our study has many limitations: First, StAR expression in normal oligodendrocytes was not performed; second, study for glioblastoma, a more malignant tumor than high-grade OD, is required; third, extensive studies over more stable cell lines or more tissues are necessary.

In conclusion, the pattern of expression between low- and high-grade ODs can differ. This study suggests that the mechanism of neurosteroids synthesis through StAR can be related to the growth of ODs.

\section{Acknowledgements}

This study was supported by a grant of the Seoul National University Hospital (grant number: 32004031).

\section{References}

1. Puduvalli VK, Hashmi M, McAllister LD, Levin VA, Hess KR, Prados M, Jaeckle KA, Yung WK, Buys SS, Bruner JM, Townsend JJ, Davis R, Sawaya R and Kyritsis AP: Anaplastic oligodendrogliomas: prognostic factors for tumor recurrence and survival. Oncology 65: 259-266, 2003.

2. Popko B, Pearl DK, Walker DM, Comas TC, Baerwald KD, Burger PC, Scheithauer BW and Yates AJ: Molecular markers that identify human astrocytomas and oligodendrogliomas. J Neuropathol Exp Neurol 61: 329-338, 2002.

3. Brown RC, Cascio C and Papadopoulos V: Pathways of neurosteroid biosynthesis in cell lines from human brain: regulation of dehydroepiandrosterone formation by oxidative stress and beta-amyloid peptide. J Neurochem 74: 847-859, 2000.

4. Yu L, Romero DG, Gomez-Sanchez CE and Gomez-Sanchez EP: Steroidogenic enzyme gene expression in the human brain. Mol Cell Endocrinol 190: 9-17, 2002.

5. Stocco DM and Clark BJ: Regulation of the acute production of steroids in steroidogenic cells. Endocr Rev 17: 221-244, 1996. 
6. Iwahashi K, Ozaki HS, Tsubaki M, Ohnishi J, Takeuchi Y and Ichikawa Y: Studies of the immunohistochemical and biochemica localization of the cytochrome P-450scc-linked monooxygenase system in the adult rat brain. Biochim Biophys Acta 1035: 182-189, 1990 .

7. Mellon SH and Griffin LD: Neurosteroids: biochemistry and clinical significance. Trends Endocrinol Metab 13: 35-43, 2002.

8. Huang H, Okamoto Y, Yokoo H, Heppner FL, Vital A, FevreMontange M, Jouvet A, Yonekawa Y, Lazaridis EN, Kleihues P and Ohgaki $\mathrm{H}$ : Gene expression profiling and subgroup identification of oligodendrogliomas. Oncogene 23: 6012-6022, 2004.

9. Mehrian Shai R, Reichardt JK, Ya-Hsuan H, Kremen TJ, Liau LM, Cloughesy TF, Mischel PS and Nelson SF: Robustness of gene expression profiling in glioma specimen samplings and derived cell lines. Brain Res Mol Brain Res 136: 99-103, 2005.

10. Shai R, Shi T, Kremen TJ, Horvath S, Liau LM, Cloughesy TF, Mischel PS and Nelson SF: Gene expression profiling identifies molecular subtypes of gliomas. Oncogene 22: 4918-4923, 2003.

11. Watson MA, Perry A, Budhraja V, Hicks C, Shannon WD and Rich KM: Gene expression profiling with oligonucleotide microarrays distinguishes World Health Organization grade of oligodendrogliomas. Cancer Res 61: 1825-1829, 2001.

12. Hallahan AR, Pritchard JI, Chandraratna RA, Ellenbogen RG, Geyer JR, Overland RP, Strand AD, Tapscott SJ and Olson JM: BMP-2 mediates retinoid-induced apoptosis in medulloblastoma cells through a paracrine effect. Nat Med 9: 1033-1038, 2003.

13. Phillips HS, Kharbanda S, Chen R, Forrest WF, Soriano RH, Wu TD, Misra A, Nigro JM, Colman H, Soroceanu L, Williams PM, Modrusan Z, Feuerstein BG and Aldape K: Molecular subclasses of high-grade glioma predict prognosis delineate a pattern of disease progression, and resemble stages in neurogenesis. Cancer Cell 9: 157-173, 2006.

14. Somasundaram K, Reddy SP, Vinnakota K, Britto R, Subbarayan M, Nambiar S, Hebbar A, Samuel C, Shetty M, Sreepathi HK, Santosh V, Hegde AS, Hegde S, Kondaiah P and Rao MR: Upregulation of ASCL1 and inhibition of Notch signaling pathway characterize progressive astrocytoma. Oncogene 24: 7073-7083, 2005.

15. Rorive S, Maris C, Debeir O, Sandras F, Vidaud M, Bieche I, Salmon I and Decaestecker C: Exploring the distinctive biological characteristics of pilocytic and low-grade diffuse astrocytomas using microarray gene expression profiles. J Neuropathol Exp Neurol 65: 794-807, 2006.
16. Ram R, Lorente G, Nikolich K, Urfer R, Foehr E and Nagavarapu U: Discoidin domain receptor-1a (DDR1a) promotes glioma cell invasion and adhesion in association with matrix metalloproteinase-2. J Neurooncol 76: 239-248, 2006.

17. Kim HJ, Kim JE, Ha M, Kang SS, Kim JT, Park IS, Paek SH, Jung HW, Kim DG, Cho GJ and Choi WS: Steroidogenic acute regulatory protein expression in the normal human brain and intracranial tumors. Brain Res 978: 245-249, 2003.

18. Nygren C, von Holst H, Mansson JE and Fredman P: Increased levels of cholesterol esters in glioma tissue and surrounding areas of human brain. Br J Neurosurg 11: 216-220, 1997.

19. VanDoren MJ, Matthews DB, Janis GC, Grobin AC, Devaud LL and Morrow AL: Neuroactive steroid 3alpha-hydroxy-5alphapregnan-20-one modulates electrophysiological and behavioral actions of ethanol. J Neurosci 20: 1982-1989, 2000.

20. Assimakopoulou M, Sotiropoulou-Bonikou G, Maraziotis T and Varakis J: Does sex steroid receptor status have any prognostic or predictive significance in brain astrocytic tumors? Clin Neuropathol 17: 27-34, 1998.

21. Langeveld CH, van Waas MP, Stoof JC, Sutanto W, de Kloet ER Wolbers JG and Heimans JJ: Implication of glucocorticoid receptors in the stimulation of human glioma cell proliferation by dexamethasone. J Neurosci Res 31: 524-531, 1992.

22. Pinski J, Halmos G, Shirahige Y, Wittliff JL and Schally AV: Inhibition of growth of the human malignant glioma cell line (U87MG) by the steroid hormone antagonist RU486. J Clin Endocrinol Metab 77: 1388-1392, 1993.

23. Weidenfeld J and Schiller H: Metabolism of steroids by human brain tumors. Clin Neuropharmacol 7: 395-397, 1984.

24. Khalid H, Shibata S, Kishikawa M, Yasunaga A, Iseki M and Hiura T: Immunohistochemical analysis of progesterone receptor and $\mathrm{Ki}-67$ labeling index in astrocytic tumors. Cancer 80: 2133-2140, 1997.

25. Kim HJ, Kang SS, Cho GJ and Choi WS: Steroidogenic acute regulatory protein: its presence and function in brain neurosteroidogenesis. Arch Histol Cytol 67: 383-392, 2004.

26. King SR, Manna PR, Ishii T, Syapin PJ, Ginsberg SD, Wilson K, Walsh LP, Parker KL, Stocco DM, Smith RG and Lamb DJ: An essential component in steroid synthesis, the steroidogenic acute regulatory protein, is expressed in discrete regions of the brain. J Neurosci 22: 10613-10620, 2002. 